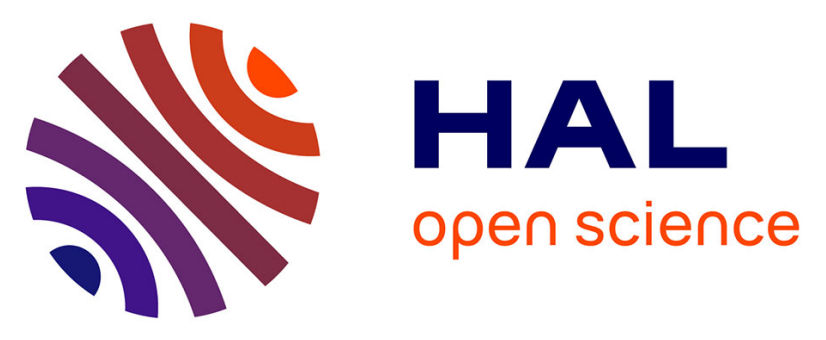

\title{
Evaluation of the analytical performances of avidin-modified carbon sensors based on mediated horseradish peroxidase enzyme label and their application to the amperometric detection of nucleic acids
}

Naima Djellouli, Murielle Rochelet-Dequaire, Benoit Limoges, Michel Druet, Pierre Brossier

\section{- To cite this version:}

Naima Djellouli, Murielle Rochelet-Dequaire, Benoit Limoges, Michel Druet, Pierre Brossier. Evaluation of the analytical performances of avidin-modified carbon sensors based on mediated horseradish peroxidase enzyme label and their application to the amperometric detection of nucleic acids. Biosensors and Bioelectronics, 2007, 22, pp.2906-2913. 10.1016/j.bios.2006.12.006 . hal-00442897

\author{
HAL Id: hal-00442897 \\ https://hal.science/hal-00442897
}

Submitted on 23 Dec 2009

HAL is a multi-disciplinary open access archive for the deposit and dissemination of scientific research documents, whether they are published or not. The documents may come from teaching and research institutions in France or abroad, or from public or private research centers.
L'archive ouverte pluridisciplinaire HAL, est destinée au dépôt et à la diffusion de documents scientifiques de niveau recherche, publiés ou non, émanant des établissements d'enseignement et de recherche français ou étrangers, des laboratoires publics ou privés. 


\section{Evaluation of the analytical performances of avidin-modified carbon}

sensors based on a mediated horseradish peroxidase enzyme label and their application to the amperometric detection of nucleic acids

Naïma Djellouli ${ }^{\mathrm{a}}$, Murielle Rochelet-Dequaire, ${ }^{\mathrm{a}^{*}}$ Benoît Limoges ${ }^{\mathrm{b}}$, Michel Druet $^{\mathrm{b}}$, Pierre Brossier ${ }^{\mathrm{a}}$

a Laboratoire de Microbiologie Médicale et Moléculaire, Facultés de Médecine et de Pharmacie, 7 Boulevard Jeanne d'Arc, 21000 Dijon, France

${ }^{b}$ Laboratoire d'Electrochimie Moléculaire, UMR CNRS 7591, Université Paris 7-Denis Diderot, 2 place Jussieu, 75251 Paris Cedex 05, France

* Corresponding author. Tel : 33380393254 ; Fax: 33380293604

e-mail address : Murielle.Dequaire@u-bourgogne.fr 


\section{Abstract}

In this study, neutravidin-coated screen-printed carbon sensors were fully characterized and further used for the amperometric detection of specific DNA sequences of human cytomegalovirus (HCMV DNA). For this purpose, we took advantage of an earlier established relationship between the amount of HRP affinity immobilized on the surface of the electrode and the steady-state current recorded in the presence of $\mathrm{H}_{2} \mathrm{O}_{2}$ as substrate and the single electron donor $\left[\mathrm{Os}{ }^{\mathrm{III}}(\mathrm{bpy})_{2} \mathrm{pyCl}^{2+}\right.$ as cosubstrate. After incubating a saturating concentration of biotinylated horseradish peroxidase (Bio-HRP) onto the neutravidinmodified sensors, a surface concentration of active HRP of $3.6 \mathrm{pmol} . \mathrm{cm}^{-2}$ was calculated from the measurement of the electrocatalytic plateau current value. This result indicates that monolayers of neutravidin were adsorbed on the screen-printed carbon sensors. These neutravidin-covered platforms were then used to immobilize biotinylated nucleic acid targets. After hybridization with a complementary digoxigenin-labeled detection probe, the extent of hybrids formed was determined with an anti-digoxigenin HRP conjugate. The biosensor assay was applied to the detection of a synthetic oligonucleotide target, and then to the determination of an amplified viral DNA sequence. Monolayers of HRP-labeled oligonucleotide hybrids were immobilized onto the sensing surface whereas one third of the surface was covered with HCMV DNA hybrids. On the other hand, detection limits of 200 $\mathrm{pM}$ and $1 \mathrm{nM}$ were obtained for the short oligonucleotide and the longer DNA targets, respectively. Finally, we demonstrated that the sensitivity of the electrochemical assay could be significantly improved by using high concentrations of the reduced form of the mediator $\left[\mathrm{Os}^{\mathrm{II}}(\mathrm{bpy})_{2} \mathrm{pyCl}\right]^{+}$, thus allowing one to detect as low as $30 \mathrm{pM}$ of amplified HCMV DNA fragment.

Keywords: HRP, Electrocatalytic Mechanism, Screen-printed carbon electrode, Avidin, DNA biosensor array, Virus. 


\section{Introduction}

Electrochemical DNA sensors have received considerable attention these past years because electrochemical transducers offer a simple, sensitive, and inexpensive platform to detect nucleic acids binding (Lucarelli et al., 2004). Moreover, their compatibility with modern microfabrication and miniaturization, as well as their low-power requirement makes such devices excellent candidates for on-site DNA assays. The principle of a DNA electrochemical sensor basically consists to convert a nucleic acid hybridization event engendered at an electrode surface into a useful electrical signal. Various electrochemical detection strategies have been investigated, including label-free measurements (Wang et al., 2002), redox active hybrid indicators (Millan et al., 1993), mediated oxidation of guanine in DNA strands (Gore et al., 2003), metal nanoparticles tags (Authier et al., 2001), and redox (Anne et al., 2003) or enzyme labels (De Lumley-Woodyear et al., 1996). Because of their high amplification of the signal through catalytic generation of a large number of electroactive molecules (i.e., high turnover number), enzyme labels have led to the most sensitive electrochemical detection schemes of DNA hybridization. This has been demonstrated with various enzymes labels such as the horseradish peroxidase (De Lumley-Woodyear et al., 1996; Azek et al., 2000; Campbell et al., 2002; Dequaire et al., 2002; Marchand et al., 2005), soybean peroxidase (Caruana et al., 1999), alkaline phosphatase (Bagel et al., 2000; Aguilar et al., 2003; Carpani et al., 2004; Hernández-Santos et al., 2004; Nebling et al., 2004), PQQdependent glucose dehydrogenase (Ikebukuro et al., 2002), bilirubin oxidase (Kim et al., 2004), and glucose oxidase (Kavanagh et al., 2006). Among these enzyme labels the HRP is undoubtedly an excellent choice because of its high turnover, commercial availability, low cost, high stability and easy coupling with many biomacromolecules without significant loss of its catalytic activity. Transduction of HRP activity into an electrochemical response can 
result either from the catalytic conversion of an electron donor cosubstrate into an electroactive product (Azek et al., 2000; Marchand et al., 2005) or a redox-mediated electrocatalytic reduction of hydrogen peroxide (De Lumley-Woodyear et al., 1996). This latter approach, which offers the advantages of being volume- and reaction time-independent, was first demonstrated for nucleic acid detection by Heller and his colleagues by using a redox-polymer film-coated electrode that wired and mediated a HRP-labeled oligonucleotides hybridized on its surface (De Lumley-Woodyear et al., 1996). The method was subsequently applied to the development of diverse highly sensitive DNA or RNA assays (Caruana et al., 1999; Campbell et al., 2002; Dequaire et al., 2002). In these applications, the quantity of nucleic acid hybrids formed onto the electrode surface is proportional to the amount of HRP label attached to the hybrids, and thus to the electrocatalytic current generated by the enzyme.

At this stage, a precise knowledge of the relationship that links the enzyme catalytic current response to the amount of target DNA anchored onto the electrode surface, and thus indirectly to the target DNA concentration initially present in the bulk of the solution, would be useful to rationalize and optimize the analytical performances of electrochemical DNA sensors. It would be also helpful for comparison with other enzyme-amplified amperometric DNA sensors. To reach this goal it is first necessary to have a precise knowledge of the quantity of enzyme label indirectly immobilized through DNA hybridization on the electrode surface. It can be obtained from the magnitude of the catalytic current response and the characteristic kinetics rate constants associated to the enzyme mechanism. Secondly, with the aim to correlate the amount of DNA target hybridized on the electrode surface to its initial concentration in the assay solution, a well comprehension of the thermodynamics and kinetics that govern the target DNA mass transport and recognition to the electrode surface is required (Bourdillon et al., 1999). Despite a HRP mechanism complicated by a substrate inhibition/cosubstrate reactivation (Dequaire et al., 2002), the relationship between the 
quantity of HRP affinity immobilized on the surface of an electrode and the steady-state catalytic current recorded in the presence of the reversible one-electron mediator $\left[\mathrm{Os}(\mathrm{bpy})_{2} \mathrm{pyCl}\right]^{2+}$ (with bpy $=$ bipyridine and py $=$ pyridine) and $\mathrm{H}_{2} \mathrm{O}_{2}$ substrate was successfully established (Limoges et al., 2003).

In the present work, we have applied these earlier results to characterize the analytical performances of a HRP-amplified electrochemical DNA sensor. For such a purpose, we took advantage of home-made disposable arrays of screen-printed carbon electrodes (SPE), specifically designed by us, for high throughput amperometric measurements with a multiplexed potentiostat (Limoges et al., submitted). For the immobilization of nucleic acids onto the surface of the electrode, we first reinvestigated the passive adsorption strategy used in our previous work (Azek et al., 2000). Since this latter yielded very low HRP-labeled hybrids surface coverage, we selected a simple and efficient alternative approach, which consists in passively adsorbing a first layer of avidin on the surface of the carbon electrodes, followed by a specific attachment of biotinylated nucleic acids. Our choice was guided by the fact that such an approach was previously shown to be very efficient for the reproducible immobilization of biotinylated enzyme. It was for example observed that submicromolar concentrations of enzyme were sufficient to saturate a solid surface with a closed-packed monolayer of biotinylated enzyme (Limoges et al., 2006). Moreover, such an enzyme immobilization procedure was shown to preserve the catalytic activity of the enzyme from partial denaturation or conformational changes, probably because of an increase of the electrode surface biocompatibility (Limoges et al., 2003). Avidin-coated electrodes were also shown to be suitable for the immobilization of biotinylated oligonucleotide probes on electrode surface, leaving the probes accessible to hybridization with their complementary sequences (Hernández-Santos et al., 2004; Carpini et al., 2004). 
The avidin-modified electrodes were first characterized and tested with the capture of biotinylated synthetic oligonucleotide sequence, followed by its hybridization with a complementary digoxygenin-labeled oligonucleotide probe and an enzyme labeling by an anti-digoxigenin antibody conjugated to HRP (anti-Dig-HRP). The activity of HRP specifically attached to the electrode was at last electrochemically quantified after addition of $\mathrm{H}_{2} \mathrm{O}_{2}$ and $\left[\mathrm{Os}(\mathrm{bpy})_{2} \mathrm{pyCl}^{2+}\left(\mathrm{Os}^{\mathrm{III}}\right)\right.$. As application for DNA target detection, the sensing platform was also investigated for the hybridization assay of a DNA sequence from human cytomegalovirus (HCMV). The HCMV is an important pathogen from the family of herpes virus and its diagnostics is important in transplant, encephalitis, neurological syndromes, opportunistic infections in immune-suppressed patients, or screening of blood donations. A 406-base pair HCMV DNA was obtained by PCR amplification with biotinylated primers in such a way to produce biotinylated targets. In contrast to the previous electrochemical DNA hybridization assays based on a avidin-biotin linkage (Carpini et al., 2004; Hernández-Santos et al., 2004; Ikebukuro et al., 2002; Metfies et al., 2005; Williams et al., 2003), this approach allows the direct attachment of the target DNA sequence onto the avidin-coated electrode without passing trough the intermediary of a biotinylated capture probe.

\section{Experimental section}

\subsection{Reagents and solutions}

Hydrogen peroxide $(\sim 50 \%)$, which concentration was determined by permanganate titration, and Tween 20 were supplied by Prolabo (France). The osmium complex $\left[\mathrm{Os}^{\mathrm{II}}(\mathrm{bpy})_{2} \mathrm{pyCl}-\mathrm{PF}_{6}\right.$ was synthesized as previously described (Kober et al., 1988) and was

reacted with $\mathrm{AgPF}_{6}$ (Aldrich, ) to obtain its oxidized form [Os $\left.{ }^{\mathrm{III}}(\mathrm{bpy})_{2} \mathrm{pyCl}\right]\left(\mathrm{PF}_{6}\right)_{2}$. Lyophilized bovine serum albumin (BSA, fraction V) was provided from Sigma. Lyophilized 
NeutrAvidin $^{\mathrm{TM}}$ and lyophilized biotinylated horseradish peroxidase (Bio-HRP), which concentration was determined spectrophotometrically using the Soret extinction coefficient of $102 \mathrm{mM}^{-1} \cdot \mathrm{cm}^{-1}$ at $403 \mathrm{~nm}$, were purchased from Pierce (USA). Lyophilized Fab fragments from anti-digoxigenin antibody from sheep, conjugated with horseradish peroxidase (antiDig-HRP) were obtained from Roche Diagnostics GmbH (Germany).

The 5'-biotinylated primers (Bio-AC1 and Bio-AC2) used to PCR-amplify a 406-bp HCMV target and the 5'-digoxigenin-labeled HCMV target specific detection probes (DigAC3, Dig-AC4, Dig-B1 and Dig-AC'1) were gift from Argene SA. All of these sequences are the proprietary of Argene SA, as well as the Hybridowell ${ }^{\circledR}$ kit which reagents (hybridization and washing buffers, ETS2 negative control) were used in this work. Taq polymerase, Taq polymerase buffer and the four nucleotide bases (dNTPs) were purchased from Qiagen (France). Low DNA Mass Ladder $^{\circledR}$ for electrophoresis quantification was obtained from Invitrogen (France).

The phosphate buffer solution (PBS, $4.3 \mathrm{mM} \mathrm{NaH}_{2} \mathrm{PO}_{4}, 15.1 \mathrm{mM} \mathrm{Na}_{2} \mathrm{HPO}_{4}$ and 50 $\mathrm{mM} \mathrm{NaCl} ; \mathrm{pH}=7.4$ ) and all of the other aqueous solutions were prepared using water purified by an Elgastat water system (Elga, France). All reagents were of analytical grade and used without further purification.

\subsection{Apparatus and electrodes}

High impact polystyrene substrate (HIPS) was purchased from Sericol (Vaux-enVelin, France) as 1-m-long, 70-cm-wide, 1-mm-thick plates. Small rectangles (8 cm long and $5 \mathrm{~cm}$ wide) were cut, cleaned with ethanol and left to dry at room temperature before using their mat side as printing substrate. Conductive carbon-based (Electrodag ${ }^{\circledR}$ PF 107A) and silver-based (Electrodag® 6038 SS) inks were obtained from Acheson Colloids (Port Huron, MI) and the insulating ink from Gwent Electronics Materials LTD (UK). Disposable arrays of 
eight sensors were screen-printed in house using a Presco screen-printing machine (USA) according the following three-step procedure. Carbon-based disk-shaped working electrodes were first screen-printed on the polymeric substrate. Two insulating layers were then printed over the array of eight electrodes, leaving uncovered sensing surface areas of $4.9 \mathrm{~mm}^{2}$ and the electric contacts. Ring-shaped layers of a carbon/silver ink (carbon to silver ratio 3:2) to which all potentials were referenced (vs. pseudo $\mathrm{Ag} / \mathrm{AgCl}$ ) were further printed around the working areas and constituted the reservoirs for small-volume electrochemical cells. After each screen-printing step, the ink was left to dry at room temperature and cured as recommended by the manufacturer (carbon and carbon/silver inks: $60^{\circ} \mathrm{C}$ for $1 \mathrm{~h}$ and insulating ink: $80^{\circ} \mathrm{C}$ for $\left.3 \mathrm{~h}\right)$.

Individual cyclic voltammetric measurements were performed with an Autolab potentiostat (PGSTAT 12, ECO Chemie, Utrecht, NL) interfaced to a PC system with GPES version 4.4 software. A home-made microcomputer-assisted eight-channel potentiostat, which construction will be detailed in a future work, was used to simultaneously measure the eight positions of the SPE array by chronoamperometry (Limoges et al., submitted). Unless otherwise stated, the amount of HRP labels bound to the electrode surface during the last step of the assays described below was detected at room temperature by depositing onto each sensor $20-\mu \mathrm{L}$ droplets of PBS containing $2 \mathrm{mM} \mathrm{H}_{2} \mathrm{O}_{2}$ and $20 \mu \mathrm{M} \mathrm{Os}^{\mathrm{III}}$. The catalytic reduction of $\mathrm{H}_{2} \mathrm{O}_{2}$ at HRP-modified SPEs in the presence of Os ${ }^{\mathrm{III}}$ was measured either by cyclic voltammetry (scan rate of $10 \mathrm{mV} . \mathrm{s}^{-1}$ ) or by chronoamperometry (step potential from $+0.5 \mathrm{~V}$ to $-0.3 \mathrm{~V} v s$. pseudo $\mathrm{Ag} / \mathrm{AgCl}$ after $60 \mathrm{~s})$.

\subsection{Preparation of the biosensing surfaces}

Unless otherwise stated, all the incubations were performed at room temperature in a water-saturated atmosphere. 
A drop of $20 \mu \mathrm{L}$ of a $0.5 \mathrm{mg} \cdot \mathrm{mL}^{-1}$ neutravidin solution in PBS was placed onto each working electrode surface and incubated for $2 \mathrm{~h}$. The surface of each sensor was then carefully rinsed with PBS to remove the excess of neutravidin and the array of sensors was dipped in a $20-\mathrm{mL}$ bath solution containing PBS with $0.1 \%(\mathrm{w} / \mathrm{v})$ BSA (PBS-BSA) for 30 min. After another thorough wash in a PBS bath, the resulting biosensing platform was stored in PBS at $4^{\circ} \mathrm{C}$ until used.

\subsection{Determination of the Neutravidin surface coverage}

The specific recognition of Bio-HRP by the adsorbed neutravidin was performed by depositing and incubating $20-\mu \mathrm{L}$ drops of $0.2 \mu \mathrm{M}$ Bio-HRP in PBS-BSA on the active surface of each biosensor for $2 \mathrm{~h}$. After removing the excess of Bio-HRP, the array was rinsed in a 20$\mathrm{mL}$ bath of PBS 5 times for $1 \mathrm{~min}$. Then, the electrochemical detection was performed by dropping onto each sensing area $20 \mu \mathrm{L}$ of a mixture containing $2 \mathrm{mM} \mathrm{H}_{2} \mathrm{O}_{2}$ and $20 \mu \mathrm{M} \mathrm{Os}$ in PBS. Both voltammetric and chronoamperometric measurements were carried out as described above.

\subsection{DNA amplification by Polymerase Chain Reaction (PCR)}

HCMV DNA was extracted from cell culture as previously described (Azek et al., 2000). 5'-biotinylated primers (Bio-AC1 and Bio-AC2) were used to both amplify and biotinylate the 406-pb HCMV DNA fragment from a highly conserved region located in the HindIII "X" region of the cytomegalovirus genome US fragment (Drouet et al., 1993). The PCR was performed according to the protocol for the amplification with primers AC1/AC2 previously developed by Argene (Azek et al., 2000). Once the successful amplification confirmed by agarose gel electrophoresis, the PCR products were purified using DNA-

Microcon ${ }^{\circledR}$ devices (Millipore, Microcon Amicon, USA) following the manufacturer's 
instructions. The concentration of the purified biotinylated amplicons was finally determined by agarose gel electrophoresis.

\subsection{Hybridization assays}

These assays were performed onto the eight neutravidin-modified positions of the array using biotinylated target sequences. Unless otherwise stated, all the incubations were performed at $37^{\circ} \mathrm{C}$ in a water-saturated atmosphere.

\subsubsection{Detection of a synthetic oligonucleotide}

The Bio-AC1 target was immobilized at different concentrations (0.1 to $5000 \mathrm{nM})$ in PBS-BSA by placing $20 \mu \mathrm{L}$ of the target solution onto each position and incubating the array of biosensors for $30 \mathrm{~min}$. After removing the solution, the array was immersed in a $20-\mathrm{mL}$ bath of PBS five times for $1 \mathrm{~min}$ and $20-\mu \mathrm{L}$ drops of the 5'-digoxigenin labeled complementary probe (Dig-AC'1) diluted in the hybridization buffer $(1 \mu \mathrm{M})$ were deposited onto each position and incubated for $30 \mathrm{~min}$. Next, the array was subjected to a washing cycle consisting of five rinses for $1 \mathrm{~min}$ in a $20-\mathrm{mL}$ bath of fresh $1 \mathrm{X}$ washing solution. Following this step, drops of $20 \mu \mathrm{L}$ containing anti-Dig-HRP (1/10 dilution in PBS-BSA containing 0.1 $\%(\mathrm{v} / \mathrm{v})$ Tween 20$)$ were deposited onto the active surfaces of the array and incubated for 30 min. A last washing cycle was then performed with PBS-BSA containing $0.1 \%(\mathrm{v} / \mathrm{v})$ Tween 20 followed by PBS (five $20-\mathrm{mL}$ bath for 1 min each with each buffer). After carefully removing the rinsing solution, the electrochemical detection was performed by dropping onto each electrode $20 \mu \mathrm{L}$ of PBS containing $2 \mathrm{mM} \mathrm{H}_{2} \mathrm{O}_{2}$ and $20 \mu \mathrm{M} \mathrm{Os}{ }^{\mathrm{III}}$. Both voltammetric and chronoamperometric measurements were carried out as described in the Section 2.2. 


\subsubsection{Detection of the amplified 406-bp HCMV DNA sequence}

After purification and quantification, the double-stranded HCMV DNA samples were thermally denaturated by heating for $20 \mathrm{~min}$ at $95^{\circ} \mathrm{C}$, diluted in the PCR negative control with concentrations ranging from 0.06 to $1000 \mathrm{nM}$ then cooled in an iced bath. Meanwhile, complementary probes tagged with a digoxigenin label (Dig-B1, Dig-AC3 and Dig-AC4), were prepared at a final concentration of $1 \mu \mathrm{M}$ in the hybridization buffer and then mixed with the DNA sample $(1: 1 \mathrm{v} / \mathrm{v}) .20-\mu \mathrm{L}$ droplets of the resulting mixture were applied onto the active surface of the biosensor array and incubated for $1 \mathrm{~h}$. Each series of experiments included the analysis of a PCR negative control (containing all of the reagents, except DNA) and a noncomplementary DNA-amplified sequence (a human ETS2 DNA gene). The subsequent post-hybridization washings, enzyme labeling and measurement procedures were the same as described above for the detection of Bio-AC1.

\section{Results and discussion}

\subsection{Construction and characterization of the neutravidin platform array}

The avidin/biotin interaction was selected to efficiently immobilize biotinylated PCRamplified nucleic acids on the surface of carbon sensor arrays. For this purpose, the neutravidin protein, a deglycosylated form of avidin (isoelectric point, $\mathrm{pI}=6.3$ ), was irreversibly adsorbed on the surface of the carbon-based electrodes. The adsorption procedure consisted in simply depositing a small drop of neutravidin solution onto the hydrophobic surface of each working electrode of the sensor array. The neutravidin form of avidin was preferred to plain avidin because of its lower propensity to undergo nonspecific adsorptions. 
The maximal binding capacity of the covered electrode toward a biotinylated macromolecule was first estimated from the saturating amount of active biotinylated HRP (Bio-HRP) that can be specifically bound to a neutravidin-coated electrode. The saturation was achieved by incubating the modified electrodes in $0.2 \mu \mathrm{M}$ Bio-HRP solution and next recording the catalytic current response in a solution containing $20 \mu \mathrm{M}$ Os ${ }^{\mathrm{III}}$ and $2 \mathrm{mM} \mathrm{H}_{2} \mathrm{O}_{2}$. With such an excess of substrate, the current is entirely controlled by kinetics of the enzyme reaction and the analytical response could be equally recorded either as a plateau-shaped curve in cyclic voltammetry or as a steady-state current in chronoamperometry. Figure 1A shows a typical set of voltammograms obtained at a carbon screen-printed electrode under the optimized procedure described in Section 2.2. In the absence of substrate (curve a), the Os ${ }^{\text {III }}$ gives rise to a one-electron reversible cyclic wave $\left(\Delta E_{\mathrm{p}}=82 \pm 12 \mathrm{mV}\right)$. Upon addition of an excess of $\mathrm{H}_{2} \mathrm{O}_{2}$, the cathodic wave is greatly increased in height, with a loss of its reversibility, to finally lead a typical plateau-shaped catalytic wave (curve a') including a characteristic hysteresis between the forward and backward traces, revealing the time-dependence of the regeneration of the active forms of the enzyme from the substrate-inactivated enzyme form. According to the HRP mechanism (the reaction scheme is recalled in a supplementary file), the surface concentration of active HRP label $\left(\Gamma^{0}\right)$ may be derived from the plateau current, $i_{p, c a t}$, using a previously established equation (Limoges et al., 2003):

$$
\Gamma^{0}=\frac{i_{p, c a t}}{2 F S k_{3} C_{p}^{0}}\left[1+\frac{C_{p}^{0}}{K_{3, M}}+\frac{k_{4} C_{s}^{0}}{\left(k_{6}+k_{5} C_{p}^{0}\right)}\right]
$$

where $i_{p, c a t}$ is derived from the experimental data simply substracting the curve obtained in the absence of $\mathrm{H}_{2} \mathrm{O}_{2}$, (curve a in Figure 1A) to that obtained in the presence of $\mathrm{H}_{2} \mathrm{O}_{2}$, (curve a' in Figure $1 \mathrm{~A}), F$ is the Faraday constant, $S$ the geometric surface area of the electrode, $C_{S}^{0}$ and $C_{P}^{0}$, the bulk concentrations of $\mathrm{H}_{2} \mathrm{O}_{2}$ substrate and $\mathrm{Os}^{\mathrm{III}}$ cosubstrate, and $K_{3, \mathrm{M}}, k_{3}, k_{4}, k_{5}$, and $k_{6}$ the relevant Michaëlis and kinetic rates constants of the reactions involved in the catalytic 
reduction of $\mathrm{H}_{2} \mathrm{O}_{2}$ by $\mathrm{HRP}$. Using the Michaëlis and kinetic rates constant values previously determined for the native HRP towards the Os ${ }^{\mathrm{III}}$ mediator, i.e. $k_{3}=7.85 \times 10^{6} \mathrm{M}^{-1} \mathrm{~s}^{-1}, k_{4}=30$ $\mathrm{M}^{-1}, k_{5}=2080 \mathrm{M}^{-1} \mathrm{~s}^{-1}, k_{6}=0.01 \mathrm{~s}^{-1}$ and $K_{3, \mathrm{M}}=37 \mu \mathrm{M}$, and considering that the HRP activity is not significantly changed after biotinylation (Limoges et al., 2006), a value of $\Gamma^{0}=3.6$ pmol.cm ${ }^{-2}$ can be calculated from the steady-state catalytic response shown in Figure 1A.

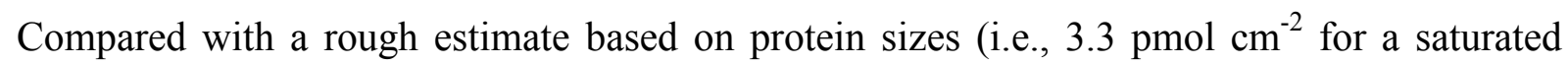
HRP monolayer) (Limoges et al., 2003), the above $\Gamma^{0}$ value is equivalent to a theoretical closed-packed monolayer of active enzyme and thus indirectly suggests the adsorption/deposition of a monolayer of neutravidin onto the electrode surface. The nonspecific binding of Bio-HRP on the protein-coated electrode was controlled by replacing the neutravidin onto the electrode surface with an adsorbed layer of BSA (curves b in Figure 1A).

A

B
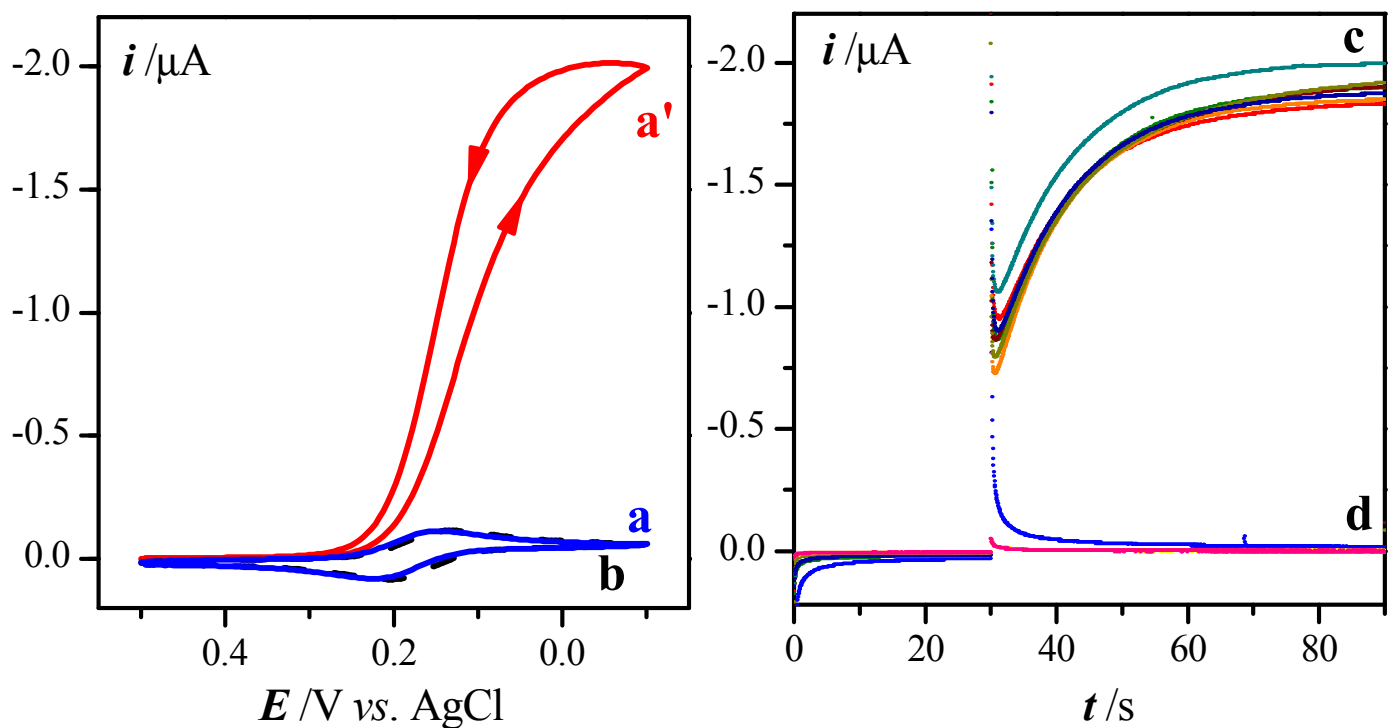

Fig. 1. (A) Cyclic voltammetric curves $\left(\mathrm{v}=10 \mathrm{mV} \cdot \mathrm{s}^{-1}\right)$ recorded at (a, a') neutravidin- or (b) BSA-coated screen-printed electrodes, first incubated in a saturating concentration of Bio$\operatorname{HRP}(0.2 \mu \mathrm{M})$ and next exposed to a PBS solution containing $20 \mu \mathrm{M}\left[\mathrm{Os}^{\mathrm{III}}(\mathrm{bpy})_{2} \mathrm{pyCl}^{2+}\right.$ and 
$2 \mathrm{mM} \mathrm{H} \mathrm{H}_{2}$. The dashed curve corresponds to the cyclic voltammogram recorded in the absence of $\mathrm{H}_{2} \mathrm{O}_{2}$. (B) Chronoamperometric responses (step potential from $+0.5 \mathrm{~V}$ to $-0.3 \mathrm{~V}$ vs. pseudo $\mathrm{Ag} / \mathrm{AgCl}$ ) simultaneously recorded at the eight positions of the sensor array. The first six positions were (c) neutravidin-coated and the two last ones were (d) BSA-coated. Recording conditions were the same conditions as above.

The Figure 1B shows a set of 8 chronoamperometric curves simultaneously recorded at an array of 8 screen-printed electrodes, where the first 6 positions (c) were coated with an adsorbed layer of neutravidin and the 2 last ones (d) with BSA followed by an overall electrodes incubation in a saturating concentration of Bio-HRP. From the magnitude of the steady-state response, an average value of $\Gamma^{0}=3.6 \pm 0.7 \mathrm{pmol} \mathrm{cm}{ }^{-2}$ was calculated, indicating a relatively good reproducibility of the neutravidin coating and Bio-HRP binding procedure (relative standard deviation of $9 \%$ ). Finally, the storage of the neutravidin-modified electrodes at $4^{\circ} \mathrm{C}$ in PBS for at least 8 weeks did not change their Bio-HRP binding capacity.

\subsection{Electrochemical detection of a synthetic oligonucleotide}

To assess the ability of the neutravidin-modified electrode arrays to efficiently bind biotinylated oligonucleotides and to yield a high hybridization rate with a complementary sequence, the avidin-modified electrodes were first investigated with a short biotinylated oligonucleotide sequence (Bio-AC1). The four main steps of the immobilization/hybridization assay procedure are illustrated in Figure 2A. The optimal experimental conditions were found after carrying out a series of preliminary experiments to evaluate the influence of several parameters such as the Dig-AC1' and anti-Dig-HRP concentrations, reaction times, temperature and buffers composition. Large excess of Dig-AC1' and anti-Dig-HRP were used in steps (ii) and (iii) with the aim to respectively hybridize the overall sequences of 
immobilized Bio-AC1 and to tag every digoxigenin moities contained in the hybrids. Incubations at $37^{\circ} \mathrm{C}$ for $30 \mathrm{~min}$ were chosen. No significant difference in signal was obtained for longer reaction times. Under these conditions, the electrochemical responses at a series of neutravidin-modified electrode sensors array were recorded for different concentrations of Bio-AC1 over the 0.1-5000 nM range.

$\mathbf{A}$

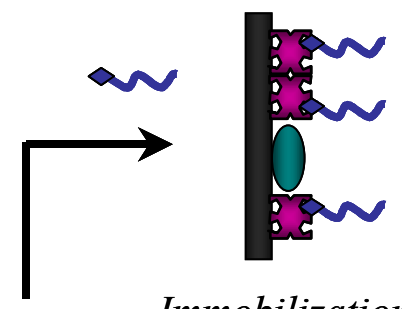

Immobilization

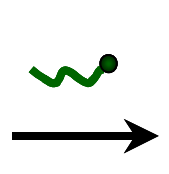

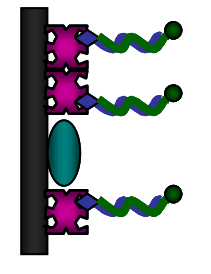

Hybridization

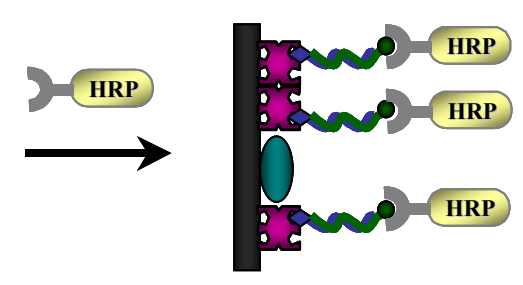

Immunoreaction

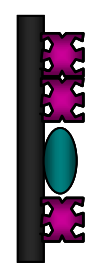

Immobilization \& Hybridization

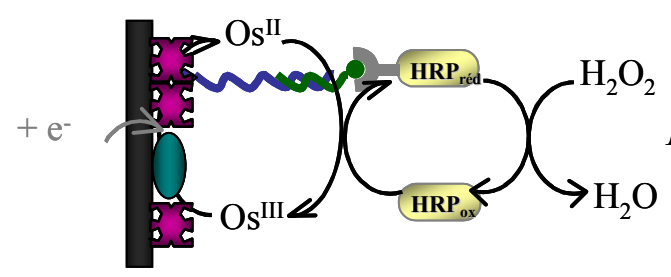

Detection
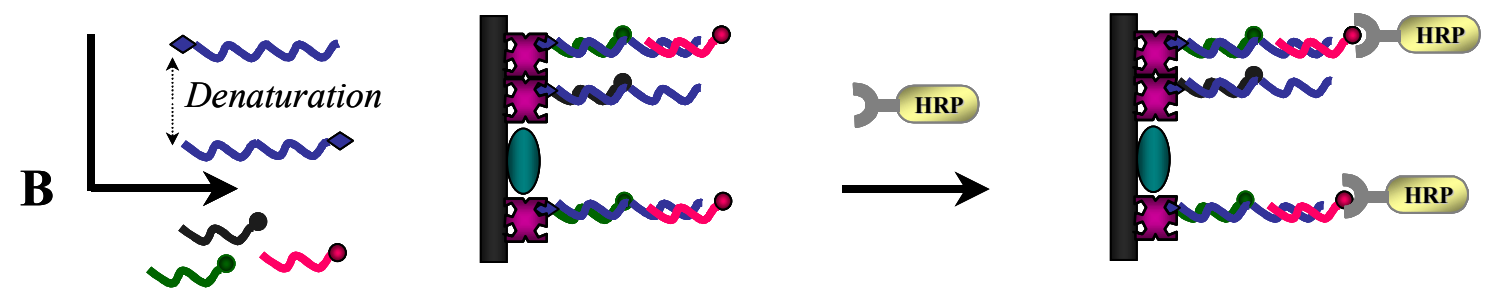

\begin{tabular}{|c|c|c|c|c|c|}
\hline 5 & 0 & $\sim$ & Ms & & HRP \\
\hline Neutravidin & BSA & $\begin{array}{l}\text { Biotinylated } \\
\text { oligonucleotide }\end{array}$ & $\begin{array}{l}\text { Biotinylated } \\
\text { HCMV DNA }\end{array}$ & $\begin{array}{l}\text { Dig-labeled } \\
\text { detection probes }\end{array}$ & Anti-Dig HRP \\
\hline
\end{tabular}

Fig. 2. Schematic representation of the analytical procedures followed for the detection of (A) oligonucleotide and (B) HCMV-amplified DNA targets with the neutravidin-coated electrochemical sensor arrays. 
The resulting logarithmic standard plot is shown in Figure 3A. The chronoamperometric signals (Figure 3B) increased with the target concentration over more than 2 decades (0.1-30 nM) and reached a limit of $2.8 \mu \mathrm{A}$. This limit indicates the saturation of the electrode by HRP-labeled hybrids. Using the eq 1 described earlier, a maximal HRP coverage of $\Gamma^{0}=3.9 \mathrm{pmol} \mathrm{cm}$ can be calculated (see also the scale on the right of Figure 3A), which is close to the maximal coverage previously obtained with Bio-HRP. It suggests, if considering one HRP-label per hybrid, that the electrode can be covered by a closed-packed monolayer of HRP-labeled hybrids up to a maximal value of $\sim 2.35 \times 10^{12}$ hybrids per $\mathrm{cm}^{2}$. Such a value competes with the maximal hybrids coverage obtained at gold electrode coated by a self-assembled monolayer of a thiol-tethered oligonuleotides (Del Giallo et al., 2005).

A

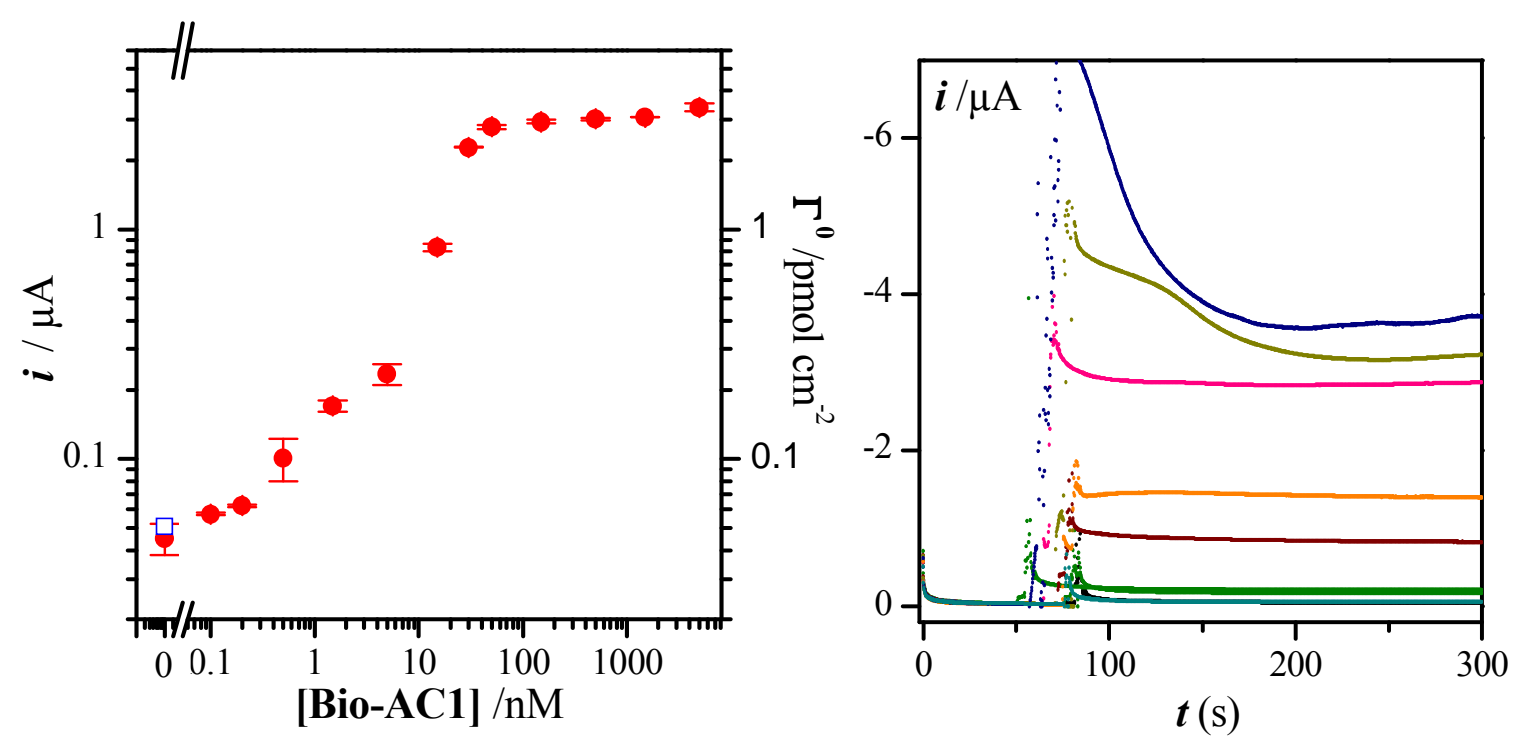

Fig. 3. (A) Log-log plot of the steady-state catalytic current and the corresponding enzymelabeled hybrids coverage, $\Gamma^{\oplus}$, versus Bio-AC1 concentration. Open square symbol: control with noncomplementary Bio-AC2. (B) Set of chronoamperometric responses simultaneously recorded with a step potential from $+0.5 \mathrm{~V}$ to $-0.3 \mathrm{~V} v s$. pseudo $\mathrm{Ag} / \mathrm{AgCl}$ after $60 \mathrm{~s}$ at the 
eight positions of the sensor array, in PBS containing $20 \mu \mathrm{M}\left[\mathrm{Os}{ }^{\mathrm{III}}(\mathrm{bpy})_{2} \mathrm{pyCl}\right]^{2+}, 2 \mathrm{mM} \mathrm{H}_{2} \mathrm{O}_{2}$ and increasing concentrations of Bio-AC1. At time $\mathrm{t}=60 \mathrm{~s}$ the substrate $\mathrm{H}_{2} \mathrm{O}_{2}$ was added and mixed for a few seconds. From top to bottom: 0, 0.1, 1.5, 5, 15, 30, 150, 500 nM Bio-AC1.

It is worth noting that the electrode surface becomes saturated at Bio-AC1 concentrations higher than $30 \mathrm{nM}$. Considering that the binding of Bio-ACl to the neutravidin-coated electrode is at equilibrium and that it follows a Langmuir isotherm, the latter value suggests an affinity binding constant of the biotinylated oligonucleotide towards the neutravidin-coated electrode within the $10^{8}-10^{9} \mathrm{M}^{-1}$ range (Bourdillon et al., 1999). Despite a lower value than the high avidin-biotin binding constant $\left(10^{15} \mathrm{M}^{-1}\right)$, the present results demonstrate that the immobilized neutravidin monolayer provides a viable and efficient platform to link a relatively high density of short biotinylated oligonucleotide sequences accessible for further hybridization. The very small current recorded in the absence of biotinylated target also shows a very low nonspecific binding of both Dig-AC1' and antiDig-HRP with the neutravidin-modified electrodes. The specificity of the assay was tested by the replacement of the Bio-AC1 sequence with a noncomplementary biotinylated oligonucleotide Bio-AC2. In that case, no measurable electrocatalytic response was recorded (open circle symbol in Figure 3A). Using a signal-to-noise ratio of 3, a detection limit of 200 $\mathrm{pM}$ of Bio-AC1 initially introduced into the hybridization solution could be estimated. The lowest detectable catalytic current response also allows to determine a minimal HRP coverage of $\Gamma^{0}{ }_{\mathrm{DL}}=60 \mathrm{fmol} . \mathrm{cm}^{-2}$. This HRP coverage detection limit is in agreement with our previous theoretical estimations (Limoges et al., 2003).

\subsection{Electrochemical detection of a PCR-amplified HCMV DNA sequence}

For practical application, we have chosen to apply our method to the assay of a PCRamplified HCMV DNA sequences of 406-bp length. The utilization of biotinylated primers 
during PCR amplification has the advantage to produce biotinylated HCMV DNA targets which can be directly bounded to the neutravidin-coated electrodes, thus avoiding the use of an intermediary biotinylated capture probe. The main steps of the assay are illustrated in Figure 2B. The experimental setup was similar to the one previously described, except that both the immobilization of the biotinylated DNA target onto the electrode and its hybridization to the mixture of digoxigenin-labeled probes were combined in a single-step. This procedure was selected since it offers the advantages to shorten and simplify the overall assay and it also leads to higher catalytic currents than the two-step procedure. Curve a in Figure 4 displays the catalytic current response as a function of target HCMV-amplified DNA over the $0.3-1000 \mathrm{nM}$ range.

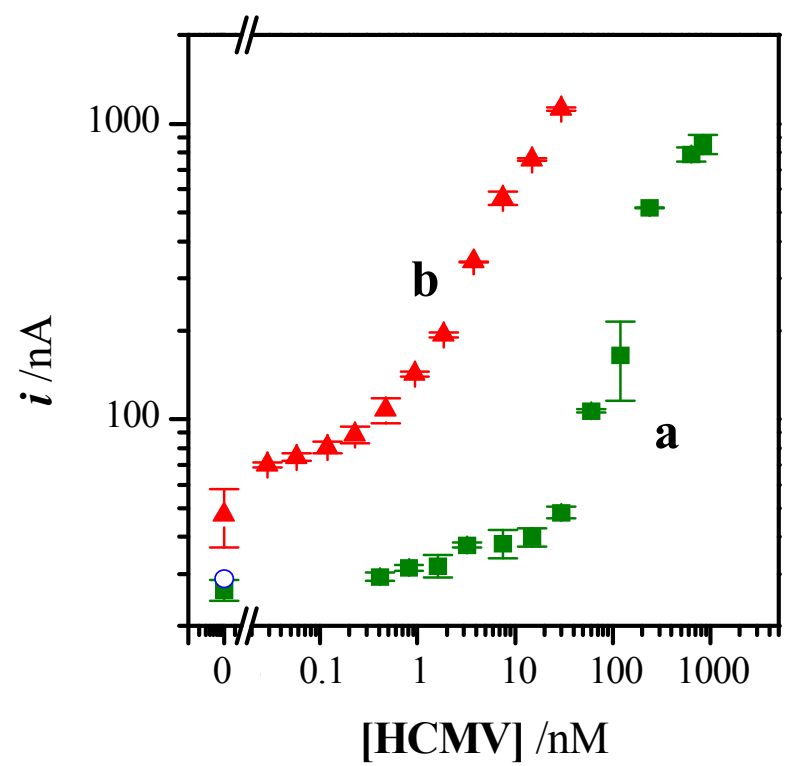

Fig. 4. Log-log plot of the steady-state catalytic current vs. HCMV DNA concentration using both redox forms of the osmium complex cosubstrate. The chronoamperometric responses (step potential from $+0.5 \mathrm{~V}$ to $-0.3 \mathrm{~V} v s$. pseudo $\mathrm{Ag} / \mathrm{AgCl}$ ) were recorded at the sensor array in the presence of $2 \mathrm{mM} \mathrm{H} \mathrm{H}_{2} \mathrm{O}_{2}$ and (a) $20 \mu \mathrm{M}\left[\mathrm{Os}{ }^{\mathrm{III}}(\mathrm{bpy})_{2} \mathrm{pyCl}\right]^{2+}$ or (b) $100 \mu \mathrm{M}$ [Os $\left.^{\mathrm{II}}(\mathrm{bpy})_{2} \mathrm{pyCl}\right]^{+}$in PBS. Open circle symbol: control with a noncomplementary human ETS2 DNA sequence performed with $20 \mu \mathrm{M}$ [Os $\left.^{\mathrm{III}}(\mathrm{bpy})_{2} \mathrm{pyCl}\right]^{2+}$. 
The absence of electrocatalytic currents for the PCR negative control (full square symbol of curve a in Figure 4) and the biotinylated PCR-amplified noncomplementary fragment of human ETS2 gene (open circle symbol of curve a in Figure 4) confirmed the good selectivity of the PCR amplification and electrochemical DNA hybridization assay. The current response increases linearly with the concentration of target HCMV DNA in the range of 30 to $200 \mathrm{nM}$. At higher concentrations, the current levels off at a value of $\sim 1 \mu \mathrm{A}$, thus allowing to estimate a saturating HRP-label coverage of $\sim 1 \mathrm{pmol} \mathrm{cm}$. This saturating value is the third of that previously obtained for the short oligonucleotide target. Such a result can be explained by the larger size of the 406-bp HCMV DNA fragments which should occupy a larger area on the electrode. It should be also the result of lower hybridization efficiency owing to increasing steric effects with long immobilized DNA sequences. A detection limit of $1 \mathrm{nM}$ HCMV DNA was estimated. After recasting eq 1 as follows:

$$
i_{p, c a t}=\frac{2 F S k_{3} C_{P}^{0} \Gamma^{0}}{1+\frac{C_{P}^{0}}{K_{3, M}}+\frac{k_{4} C_{S}^{0}}{\left(k_{6}+k_{5} C_{P}^{0}\right)}}
$$

it appears that the catalytic plateau current can be enhanced by increasing the mediator concentration, thereby allowing to improve the sensitivity of the HRP label detection. However, at high Os ${ }^{\mathrm{III}}$ concentrations, the contribution of the Os ${ }^{\mathrm{III}}$ reduction to the total steady-state current becomes non-negligible and thus tends to decrease the signal/background ratio. With the aim to reduce such a contribution, we have decided to start from the reduced form of the mediator $\left(\mathrm{Os}^{\mathrm{II}}\right)$. Under these conditions, the chronoamperometric response recorded in the absence of $\mathrm{H}_{2} \mathrm{O}_{2}$ provides a background current response of $4 \mathrm{nA}$ when starting from a solution containing $20 \mu \mathrm{M}$ Os ${ }^{\mathrm{II}}$. Such a value is 5-fold lower than the background current response recorded in the presence of $20 \mu \mathrm{M}$ Os ${ }^{\mathrm{III}}$. As expected, a significant improvement in sensitivity and detection limit was achieved upon increasing the mediator concentration up to $100 \mu \mathrm{M}$ Os ${ }^{\mathrm{II}}$ (compare curve $\mathrm{a}$ and $\mathrm{b}$ in Figure 4). Further 
increase in the OS ${ }^{\mathrm{II}}$ concentration was not suitable since the current response of the PCR negative and the noncomplementary ETS2 controls arose and became nonnegligible. A detection limit of $30 \mathrm{pM}$ can be estimated, which corresponds to an absolute amount of $1.8 \times$ $10^{8}$ copies HCMV DNA per electrochemical cell (i.e., $10 \mu \mathrm{L}$ of a 30 pM HCMV DNA sample incubated on the electrode surface during hybridization step). This detection limit is 500 and 300-fold higher than in our previous enzyme-amplified electrochemical HCMV DNA assays involving an HRP label with the o-phenylenediamine cosubstrate $\left(3.6 \times 10^{5}\right.$ copies per electrode) (Azek et al., 2000) and an alkaline phosphatase label $\left(6 \times 10^{5}\right.$ copies per well $)$ (Bagel et al., 2000), respectively. There are a least two reasons to explain such differences. The first one is inherent to the principle of enzyme electrocatalysis where the steady state current response gives an instantaneous measurement of the amount of enzyme label immobilized on the electrode. This approach, which is reaction-time and -volume independent, is in contrast with our earlier works where the amount of enzyme label attached to the hybrids was determined from the amount of enzyme-generated electroactive product accumulated into the bulk of the solution after a 30-min incubation period. Such an accumulation of the product led to an increase of the analytical sensitivity, and especially for a high ratio between the electrode surface area and the volume of substrate solution (Azek et al., 2000). The second reason is related to the turnover of the enzyme toward its substrates (and/or cosubstrates), which can be significantly different. In the present case, the turnover between the HRP label and the Os ${ }^{\mathrm{II}}$ complex was $290 \mathrm{~s}^{-1}\left(k_{3} \times K_{3, \mathrm{M}}\right)$. Despite this relatively good value, it is much lower than with the o-phenylenediamine cosubstrate previously used (Azek et al., 2000).

\section{Conclusion}


Under these optimized detection conditions, our biosensor assay method competes favorably with the few DNA electrochemical biosensors detection of PCR-amplified DNA products based on enzyme labels previously reported in the literature (Wojciechowski et al., 1999; Carpini et al., 2004). Owing to its advantages (simplicity, versatility, suitability for automation, compatibility with many formats of analysis), this kind of electrochemical biosensing arrays combined with an HRP-based detection is a promising tool for screening any nucleic acid sequence of interest.

\section{Acknowledgements}

The authors thank Argene SA for providing reagents and Region Bourgogne for financial support. 


\section{References}

Anne, A., Bouchardon, A., Moiroux, J., 2003. J. Am. Chem. Soc., 125, 1112-1113.

Aguilar, Z. P., Fritsch, I., 2003,. Anal. Chem. 75, 3890-3897.

Authier, L., Grossiord, C., Brossier, P., Limoges, B., 2001. Anal. Chem. 73, 4450-4456.

Azek, F., Grossiord, C., Joannes, M., Limoges, B., Brossier, P., 2000. Anal. Biochem. 284,107-113.

Bagel, O., Degrand, C., Limoges, B., Joannes, M., Azek, F., Brossier, P., 2000. Electroanalysis 12, 1447-1452.

Bourdillon, C., Demaille, C., Moiroux, J., Savéant, J-M., 1999. J. Am. Chem. Soc. 121, 24012408.

Campbell, C. N., Gal, D., Cristler, N., Banditrat, C., Heller, A., 2002. Anal. Chem. 74, 158162.

Carpini, G., Lucarelli, F., Marrazza, G., Mascini, M., 2004. Biosens. Bioelectron. 20, 167175.

Caruana, J. D., Heller, A., 1999. J. Am. Chem. Soc. 121, 769-774.

Del Giallo, M.L., Lucarelli, F., Cosulich, E., Pistarino, E., Santamaria, B., Marrazza, G., 
Mascini, M., 2005. Anal. Chem. 77, 6324-6330.

De Lumley-Woodyear, T., Campbell, C.N., Heller, A., 1996. J. Am. Chem. Soc. 118, 55045505.

Dequaire, M., Limoges, B., Moiroux, J., Savéant, J-M., 2002. J. Am. Chem. Soc. 127, 240253.

Dequaire, M., Heller, A., 2002.. Anal. Chem. 74, 4370-4377.

Drouet, E., Michelson, S., Denoyel, G., Colimon, R., 1993. J. Virol. Methods 45, 259-276.

Gore, M.R., Szalai, V.A., Ropp, P.A., Yang, I.V., Silverman, J.S., Thorp, H.H., 2003. Anal. Chem. 75, 6586-6592.

Hernández-Santos, D., Diaz-González, M., Gonzalez-García, M.B., Costa-García, A., 2004. Anal. Chem. 76, 6887-6893.

Ikebukuro, K., Kohiki, Y., Sode, K., 2002. Biosens. Bioelectron. 17, 1075-1080.

Kavanagh, P., Leech, D., 2006. Anal. Chem. 78, 2710-2716.

Kim, H. H., Zhang, Y., Heller, A., 2004. Anal. Chem. 76, 2411-2414.

Kober, E.M., Caspar, J.V., Sullivan, B.P., Meyer, T.J., 1988. Inorg. Chem. 27, 4587-4598. 
Limoges, B., Djellouli, N., Rochelet-Dequaire, M., Joannes, M., Druet, M., Brossier, P. , submitted.

Limoges, B., Marchal, D., Mavré, F., Savéant, J-M., 2006. J. Am. Chem. Soc 128, 2084-2092.

Limoges, B., Savéant, J.M., Yazidi, D. 2003.. J. Am. Chem. Soc. 125, 9192-9203.

Limoges, B., Savéant, J-M., Yazidi, D. 2006. Aust. J. Chem. 2006, 59, 257-259.

Lucarelli, F. Marrazza, G., Turner, A.P.F. Mascini, M., 2004. Biosens. Bioelectron. 19, 515530.

Marchand, G., Delattre, C., Campagnolo, R., Pouteau, P., Ginot, F., 2005. Anal. Chem. 77, 5189-5195.

Metfies, K., Huljic, S., Lange, M., Medlin, L.K., 2005. Biosens. Bioelectron. 20, 1349-1357.

Millan, K.M., Mikkelsen, S.R, 1993. Anal. Chem. 65, 2317-2323.

Nebling, E., Grunwald, T., Albers, J., Schafer, P., Hintsche, R., 2004. Anal. Chem. 76, 689696.

Wang J., Kawde A.N., 2002. Analyst, 127, 383-386. 
Williams, E., Pividori, M.I., Merkoçi, A., Forster, R.J., Alegret, S., 2003. Biosens. Bioelectron. 19, 165-175.

Wojciechowski, M., Sundseth, R., Moreno, M., Henkens, R., 1999.. Clin. Chem. 45, 16901693. 